\title{
The NF- $\kappa B$ subunit RelB regulates the migration and invasion abilities and the radio-sensitivity of prostate cancer cells
}

\author{
JIE WANG $^{1 *},{\text { SUQIN } \mathrm{YI}^{2 *}, \mathrm{JUN}^{2} \mathrm{ZHOU}^{1}, \text { YOUTAO ZHANG }^{1} \text { and FENG GUO }}^{1}$ \\ ${ }^{1}$ Central Lab, The First Affiliated Hospital of Soochow University Suzhou, Jiangsu 215006; \\ ${ }^{2}$ Department of Oncology, The First People's Hospital of Yancheng, Yancheng, Jiangsu 224000, P.R. China
}

Received December 16, 2015; Accepted April 11, 2016

DOI: 10.3892/ijo.2016.3500

\begin{abstract}
NF}-\kappa \mathrm{B}$ subunits play important roles in carcinogenesis of a variety of human malignancies and response to cancer therapy; however, the contribution of an individual subunit has not been thoroughly defined. Constitutive activation of the canonical $N F-\kappa B$ subunit is a critical event in prostate carcinogenesis. Recent findings point out that RelB, which contributes to the non-canonical NF- $\kappa \mathrm{B}$ activity, functions importantly in the prostate cancer progression. Here, we investigated systemically the functional roles of RelB in prostate cancer and examine its significance as a therapeutic target. Targeting RelB using short hairpin RNA approach in androgen-independent DU145 prostate cancer cells interfered with various biological behaviors of cells. We observed that RelB knockdown inhibited prostate cancer cell growth, migration, and invasion, and enhanced proteasome inhibitor sensitivity. The altered expression of anti-apoptotic gene Bcl-2 played critical roles in regulating both spontaneous and radiation-induced apoptosis in the presence of RelB knockdown. For the first time, we showed that RelB knockdown significantly attenuated the migration and invasion of DU145 prostate cancer cells, due to the reduction of integrin $\beta-1$. Collectively, we provided evidence that RelB functioned as an oncogene in prostate cancer. Developing a RelB-targeted therapeutic intervention, is valuable in treating advanced, metastatic prostate cancer.
\end{abstract}

\section{Introduction}

Prostate cancer is one of the most common cancer types and the second leading cause of cancer-related death in males in western countries (1). Its incidence has also kept rising in

Correspondence to: Dr Feng Guo, Central Lab, The First Affiliated Hospital of Soochow University, Shizi Road 188, Suzhou, Jiangsu 215006, P.R. China

E-mail: guofeng27@suda.edu.cn

*Contributed equally

Key words: RelB, prostate cancer cell, migration, invasion, radio-sensitivity
China during the past few years. Though surgical and radiological interventions are the most popular regimens, the lack of long-term clinical treatment options requires indentifying more effective therapeutic targets to prevent metastasis and recurrence of prostate cancer. Despite numerous reported studies, there remain many unaddressed difficulties regarding to biological mechanisms of prostate cancer initiation and progression. It is generally believed that prostate carcinogenesis is a consequence of both genetic and epigenetic modifications, converting normal prostate glandular epithelium to preneoplastic lesions and finally invasive carcinoma. To develop more specific diagnostic and prognostic biomarkers, which demands a better understanding of the molecular pathogenesis of prostate cancer, is necessary.

Nuclear factor $\kappa$-light-chain-enhancer of activated B cells $(\mathrm{NF}-\kappa \mathrm{B})$ family of transcription factors encompasses five members including RelA, RelB, c-Rel, NF- $\kappa \mathrm{B} 1$ (p50 and its precursor p105), and NF- $\mathrm{NB} 2$ (p52 and its precursor p100) in mammalian cells. NF- $\kappa \mathrm{B}$ functions critically in a range of biological processes such as inflammation, immune response, carcinogenesis, and secondary lymphoid organogenesis. In most cells, NF- $\kappa \mathrm{B}$ subunits are sequestered in the cytoplasm through binding to an inhibitory $\mathrm{I} \kappa \mathrm{B}$ family member and kept inactive. Upon stimulation, the I $\mathrm{KB}$ protein could undergo proteosomal degradation followed by the translocation of $\mathrm{NF}-\kappa \mathrm{B}$ dimers into the nucleus to transactivate their target genes. NF- $\kappa \mathrm{B}$ dimers transduce the signaling through two major pathways: the canonical and the non-canonical. The canonical NF- $\kappa \mathrm{B}$ activity involves the proteasome-mediated $\mathrm{I} \kappa \mathrm{B} \alpha$ degradation and the subsequent activation of RelAp50 heterodimers. In the non-canonical pathway, NF- $\kappa \mathrm{B} 2 /$ p100 functions as an IкB-like protein and retains RelB-p100 heterodimers in the cytoplasm. The stimulatory signaling triggers NF- $\kappa$ B2/p100 phosphorylation and proteasome-mediated degradation in an NF- $\mathrm{B}$-inducing kinase (NIK) and $\mathrm{I} \kappa \mathrm{B}$ kinase (IKK)-dependent manner, thereby producing active RelB-p52 heterodimers. The canonical NF- $\kappa$ B signaling pathway plays a role in immune responses, and inflammation whereas the non-canonical pathway is rather implicated in the secondary lymphoid organogenesis and the generation of $\mathrm{B}$ lymphocytes (2-4).

Dysregulated NF- $\mathrm{B}$ activity leads to aberrant cell proliferation and survival, angiogenesis, metastasis, and other malignant phenotypes, which contributes to the development 
of many human malignancies including prostate cancer (5). Previous studies have addressed intensively the biological significance of the canonical $\mathrm{NF}-\kappa \mathrm{B}$ activity in carcinogenesis of prostate cancer (6). Increasing attention has been paid to the understanding of the role of the non-canonical NF- $\kappa \mathrm{B}$ activity in the pathogenesis of diverse hematological malignancies and solid tumors; nevertheless, the significance of the noncanonical NF- $\mathrm{NB}$ activity in regulating the carcinogenesis of prostate cancer is still largely unclear.

RelB complexes, representing the non-canonical NF- $\kappa \mathrm{B}$ activity, is the most frequently detected NF- $\kappa \mathrm{B}$ subunit in the nucleus of prostate cancer tissue and is correlated directly with Gleason score, suggesting that RelB might be involved in prostate cancer initiation or progression (7). Both the canonical and the non-canonical NF- $\kappa \mathrm{B}$ activities are present in the androgenindependent human prostate cancer cell lines such as PC-3 and DU145, while the non-canonical NF- $\kappa \mathrm{B}$ activity is minimally expressed in the androgen-dependent prostate cancer cell line such as $\operatorname{LnCaP}(8,9)$. Therefore, it is suggested that RelB is likely implicated in the transition from androgen-dependent into androgen-independent status. RelB-targeting decreases cancer incidence and growth rate, and sensitizes prostate cancer cells to ionizing radiation. RelB exerts a radio-protective role in aggressive prostate cancer cells, partially due to the induction of the manganese superoxide dismutase (MnSOD) gene. Targeting RelB is suggested to be a valuable strategy in overcoming the radiation-resistance in both prostate and breast cancer (10-12). Recent studies have suggested that IKK $\alpha$, which is a crucial upstream molecule in the NF- $\kappa \mathrm{B}$ signaling pathway, is involved in both canonical and non-canonical NF- $\kappa \mathrm{B}$ activation, promotes malignant phenotypes of prostate cancer. IKK $\alpha$ is thereby considered to be an important therapeutic target in treating prostate cancer $(13,14)$.

Here, we examined systemically the functional roles of RelB in prostate cancer cells and studied its significance as a therapeutic target. Targeting RelB using short hairpin RNA (shRNA) approach in DU145 prostate cancer cells had an effect on varied biological behaviors of cells. Knockdown of RelB slowed down cell growth due to increased apoptosis. The downregulated expression of anti-apoptotic gene Bcl-2 played critical roles in regulating spontaneous and radiationinduced apoptosis in the presence of RelB knockdown. Importantly, RelB knockdown significantly diminished the migration and invasion abilities of DU145 prostate cancer cells, attributed at least partially to the clear reduction of integrin $\beta-1$. RelB knockdown also enhanced the sensitivity to proteasome inhibitor treatment. Collectively, we provided evidence that RelB functioned as an oncogene in prostate cancer and shows potential for targeted therapy in human prostate cancer.

\section{Materials and methods}

Tissue culture and reagents. The human prostate cancer cell line DU145 was cultured in RPMI-1640 media supplemented with $10 \%$ fetal bovine serum (FBS), $2 \mathrm{mM}$ L-glutamine, $100 \mathrm{U} / \mathrm{ml}$ penicillin, and $100 \mu \mathrm{g} / \mathrm{ml}$ streptomycin at $37^{\circ} \mathrm{C}$ in a humidified atmosphere containing $5 \% \mathrm{CO}_{2}$. Neomycin (cat no. E859-5G) was purchased from Amresco. MG-132 (cat no. 474790) was purchased from Millipore.
Cell transfection. An shRNA carrying sequence targeting the RelB gene (275-293: 5'-GCACAGATGAATTGGAGAT-3') was designed and chemically synthesized by Invitrogen (Beijing, China). The shRNA-RelB was subcloned into the pSilencer3.1H1-neo plasmid (cat no. 5770, Thermo Scientific ${ }^{\mathrm{TM}}$, China), which was linearized by restriction endonucleases HindIII and BamHI. The recombinant plasmid pSilencer3.1-siRelB (carrying an shRNA targeting RelB) and the scrambled control plasmid were then transduced into cells using Lipofectamine 2000 (cat no. 12566014, Thermo Scientific ${ }^{\mathrm{TM}}$, China) according to the manufacturer's instructions. To obtain stably transfected cell lines, cells were selected in the presence of neomycin for two weeks.

Quantitative real-time PCR ( $q R T-P C R)$. Total RNA was extracted using TRIzol reagent (Tiangen Biotech Co., Ltd., Beijing, China) according to the manufacturer's instructions. RNA yield and purity were determined spectrophotometrically at 260-280 nm and the integrity of RNA was verified by Nanodrop-1000 (Thermo Scientific). Total RNA $(2 \mu \mathrm{g})$ was reverse-transcribed with Superscript M-MLV (Promega, China) according to the manufacturer's instructions. Triplicates were performed for all reactions with a LightCycler 480 System (Roche, China). Primers for qRT-PCR were designed using Primer-BLAST (PubMed) and synthesized from Invitrogen. A housekeeping gene, $\beta$-actin, was always run together with target genes. Data were analyzed with Pfaffl method that provides a means for quantification of a target gene transcript in comparison to a reference gene (15).

Western blot analysis. RIPA buffer supplemented with proteinase inhibitor cocktail was used to prepare cell lysates. Cell lysates including whole-cell extracts and cytoplasmic/ nuclear extracts were denatured by boiling in SDS-PAGE sample buffer, fractionated on SDS-PAGE gels, and transferred onto nitrocellulose membranes. The membranes were blocked in 5\% skim milk for $1 \mathrm{~h}$ at room temperature and then incubated with the indicated primary antibodies (Abs) overnight followed by appropriate secondary Abs. Both primary and secondary Abs were diluted well in advance according to the manufacturer's instructions. Proteins were detected and scanned with an Odyssey ${ }^{\circledR}$ infrared imaging system (LI-COR Biosciences, USA). Band density was normalized to $\alpha$-tubulin, $\beta$-actin or lamin reference. Abs against Bcl-2 (C-2, sc-7382), NF- $\kappa$ B p 65 (C-20, sc-372), RelB (C-19, sc-226), c-Rel (N, sc-70), NF-B pк50 (H-119, sc-7178), NF-кB p52 (K-27, sc-298), and Lamin A/C (H-110, sc-20681) were purchased from Santa Cruz Biotechnology, Inc. Abs against Bcl-xL (\#2764), Bim (\#2819), Mcl-1 ((\#4572), Survivin (\#2808), MMP-2 (\#4022), MMP-9 (\#2270), and integrin $\beta$-1 (\#9699S) were obtained from Cell Signaling Technology. $\beta$-actin (AT0001) was purchased from CMCTAG, Inc. $\alpha$-tubulin (AJ1034a) was purchased from Abgent. IRDye 680CW (926-32222) and IRDye 800CW secondary Abs (926-32210) were obtained from LI-COR Biosciences.

Electro-mobility shift assay (EMSA). Nuclear extract preparation and EMSA were performed as previously described (16). The integrity of nuclear extracts was checked using an Oct-1 oligodeoxynucleotide probe. Briefly, nuclear extracts 
were incubated with an IRDye 800-labeled oligonucleotide probe. The binding reactions occurred under specific salt $/ \mathrm{pH}$ conditions in a binding buffer. Poly (dI:dC) (Sigma-Aldrich, China) was added to prevent non-specific binding of proteins to the $\kappa B$ oligonucleotide probe. After binding, the samples were separated on 5\% non-denaturing PAGE gels and bands were detected by scanning using Odyssey infrared imaging system.

$N F-\kappa B$ activity assay. The activity of individual NF- $\kappa \mathrm{B}$ members was quantified using an ELISA-based NF- $\mathrm{B}$ family transcription factor assay kit (Active Motif, Carlsbad, CA, USA). In brief, $2 \mu \mathrm{g}$ of nuclear extracts were incubated in a 96 -well plate with immobilized NF- $\kappa \mathrm{B}$ consensus oligonucleotides. Captured complexes were incubated with $\mathrm{NF}-\kappa \mathrm{B}$ subunit-specific primary Abs and subsequently detected with an HRP-conjugated secondary Ab, which provided a sensitive colorimetric readout at $450 \mathrm{~nm}$ that was easily quantified by spectrophotometry. All samples were tested in triplicates.

Cell growth assay. The xCelligence RTCA instrument (Roche) was applied to monitor cell growth. In the assay, impedance for indicated times was continuously monitored by the system, and the value was indicated as 'cell index', which was determined by the number of cells seeded, the overall size and morphology of the cells, and the degree to which the cells interact with the sensor surface. Following running the background blank with $100 \mu$ RPMI-1640 media supplemented with 10\% FBS, cells were seeded in wells and then the program was run. The cell index was continuously monitored by the system, and data were analyzed by RTCA software 1.2.

Cell migration and invasion assay. The cell migration and invasion assay was also performed with the xCelligence RTCA instrument. In this assay, a CIM-plate assembled with an upper and lower chamber was used. RPMI-1640 (180 $\mu \mathrm{l})$ media supplemented with $10 \%$ FBS was added to each well on the lower chamber. Cells were suspended in the serum-free media and added into the upper chamber. For the cell invasion assay, wells of the upper chamber were pre-coated with Matrigel (cat. no. 356234, BD Biosciences, China) for $\geq 4$ h. Following attachment, cell migration or invasion through Matrigel towards the lower chamber containing RPMI-1640 media supplemented with $10 \%$ FBS was continuously monitored, and data was collected and analyzed by RTCA software 1.2.

Cell cycle analysis. The cell cycle analysis and cellular DNA content measurement were carried out by flow cytometry. Cells were harvested and fixed with $70 \%$ ethanol for $24 \mathrm{~h}$ at $4^{\circ} \mathrm{C}$. Subsequently, the single cell suspensions were prepared to stain DNA using propidium iodide (PI) according to the manufacturer's instructions. Cell cycle was measured by FACSCalibur $^{\mathrm{TM}}$ cytometer (BD Biosciences) with at least three independent experiments performed.

CFSE assay. Cells $\left(1 \times 10^{6}\right)$ were suspended in $1 \mathrm{ml}$ phosphatebuffered saline (PBS) and then stained with $2 \mu \mathrm{l} \mathrm{CFSE}$ (cat no. C-1311, Molecular Probes). Afterwards, $5 \mathrm{ml}$ precooled serum-free RPMI-1640 media was added to stop the staining. After washed by RPMI-1640 media three times, cells were seeded into dishes and the fluorescence intensity was detected using FACSCalibur ${ }^{\mathrm{TM}}$ cytometer.

Scratch healing assay. The confluent cell layers were scratched using a $200 \mu \mathrm{l}$ sterile pipette tip of and washed three times with PBS. The scratched area was then imaged continuously at magnifications of x10 with the light System Microscope IX71 (Olympus, Japan). The migratory distance is used to measure the migratory ability of cells.

Gelatinase zymography. Gelatin zymography assay was performed in an $8 \%$ SDS-PAGE gel in the presence of $0.1 \%$ gelatin under non-reducing conditions. Culture media with sample buffer were loaded for SDS-PAGE with Tris-glycine SDS buffer. Samples were not boiled before electrophoresis. Following electrophoresis, the gels were washed twice in $2.5 \%$ Triton X-100 for $30 \mathrm{~min}$ at room temperature to remove SDS. The gels were then incubated at $37^{\circ} \mathrm{C}$ overnight in substrate buffer containing $50 \mathrm{mM}$ Tris- $\mathrm{HCl}$ and $10 \mathrm{mM}$ $\mathrm{CaCl}_{2}$ at $\mathrm{pH} 8.0$, and stained with $0.5 \%$ Coomassie Blue R250 in $50 \%$ methanol and $10 \%$ glacial acetic acid for $30 \mathrm{~min}$, and then destained. Upon renaturation of the enzyme, the gelatinases digested the gelatin in the gel to produce clear bands against an intensely stained background.

Apoptosis assay. Cells were harvested and stained with Annexin V and PI alone or in combination for $15 \mathrm{~min}$ at room temperature according to the manufacturer's instructions (Invitrogen, China). Cells were subjected to flow cytometric analysis with a FACSCalibur ${ }^{\mathrm{TM}}$ cytometer by using CellQuestPro software.

Irradiation treatment. Cells were cultured overnight in $100-\mathrm{mm}^{2}$ plates at a density of $2 \times 10^{6} /$ dish. Irradiation was performed using Siemens Primus-M linear accelerator at room temperature. Cells received a dose of 4 or 8 Gy per treatment at an average dose rate of $2 \mathrm{~Gy} / \mathrm{min}$. The distance between the radiation source and cells was $100 \mathrm{~cm}$. Following the radiation treatment, cells were incubated in RPMI-1640 media with $10 \%$ FBS for 24,48 and $72 \mathrm{~h}$ respectively, and harvested for the following experiments.

Statistical analysis. Data were expressed as mean \pm SD of at least three separate experiments. All statistical analysis was performed by Graphpad software. Differences between groups were valued by Student's t-test. A p-value of $\leq 0.05$ was considered significant, a p-value of $\leq 0.01$ was considered as highly significant, and a p-value of $\leq 0.001$ was considered as very highly significant.

\section{Results}

Introduction of shRNA-RelB into DU145 prostate cancer cells. To verify the functional significance of RelB in prostate carcinogenesis, a plasmid containing either shRNA-RelB or shRNA-control was constructed and then transfected into androgen-independent DU145 prostate cancer cells, respectively. Cells were cultured in the presence of neomycin $(800 \mathrm{ng} / \mu \mathrm{l})$ until single colonies appeared. The selected monoclones were further expanded and examined for the 
A

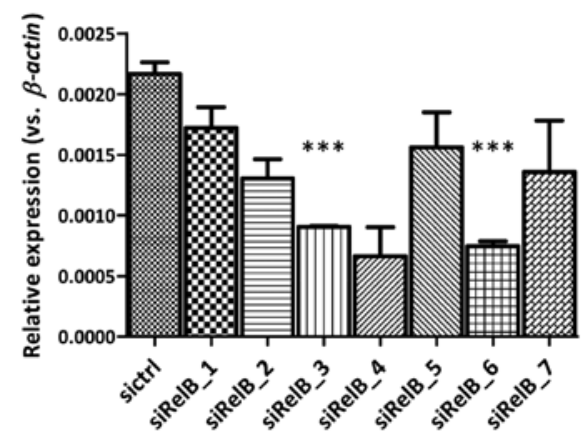

B

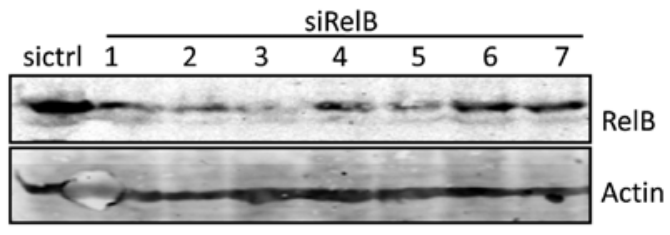

$\mathrm{C}$

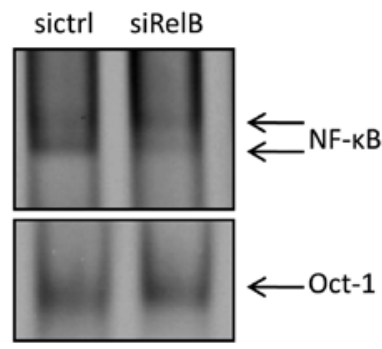

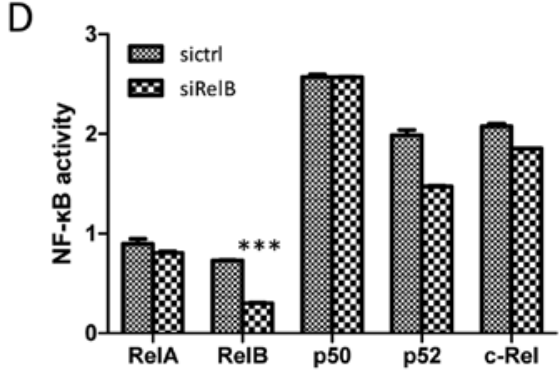

Figure 1. Establishing a RelB low-expressing cell line. (A) qRT-PCR analysis of RelB mRNA expression between the established cell lines. $\beta$-actin normalized gene expression, measured in triplicates is displayed. Data were analyzed with Pfaffl method. Significant differences are indicated (Student's t-test, $\left.{ }^{* * *} \mathrm{p}<0.001\right)$. (B) Western blot analysis for protein levels of RelB expression in the DU145-sictrl and DU145-siRelB clones. The level of each protein was normalized against actin. Independent experiments have been performed and the representative result is present. (C) Nuclear extracts of cells were prepared and tested for the

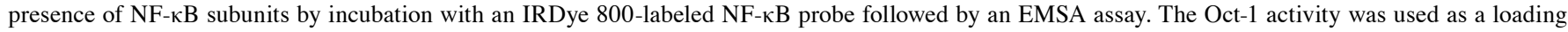
control. Arrows indicate the specific $\kappa B$-binding bands. (D) Nuclear extracts were tested for the DNA-binding activities using the TransAM ${ }^{\mathrm{TM}} \mathrm{NF}-\kappa^{\mathrm{B}}$ family transcription factor assay kit.

RelB expression. As shown in Fig. 1A, the RelB expression at mRNA level detected by qRT-PCR was generally lower in the DU145-siRelB group (transfected with the plasmid containing shRNA-RelB) as compared with that in the DU145-sictrl group (transfected with the plasmid containing shRNAcontrol), albeit at different levels. The RelB expression of clone nos. 3 and 6 in the DU145-siRelB group was significantly downregulated compared to that of the DU145-sictrl group. In line with the mRNA level, the RelB expression of clone no. 3 in the DU145-siRelB group at protein level was also evidently reduced by western blot analysis (Fig. 1B), indicating a successful RNA interference (RNAi) of the RelB gene. Therefore, DU145-siRelB clone no. 3 was chosen to carry out the following study. The $\mathrm{\kappa B}$ - DNA-binding activity in nuclear extracts of DU145-siRelB and DU145-sictrl cells was measured by EMSA. Fig. 1C shows that the upper complex was similar between the two cell lines, however, the lower complex was attenuated in the DU145-siRelB cells as compared with that in the DU145-sictrl cells. To dissect the exact contribution of RelA and RelB to the $\kappa B$-DNA

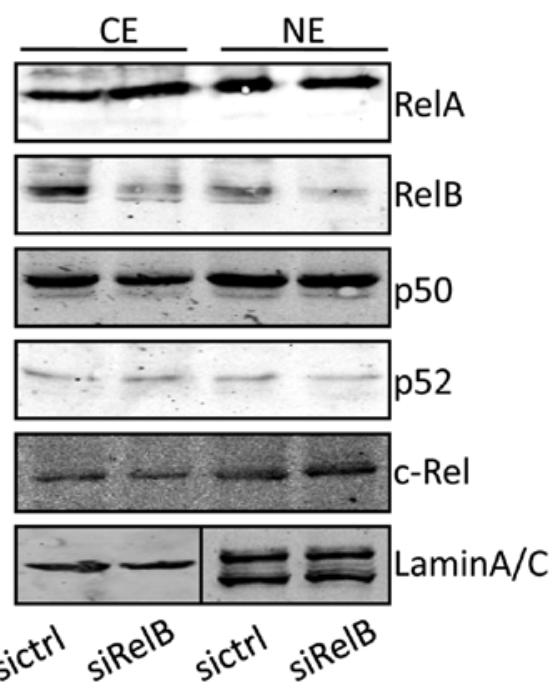

Figure 2. RelB knockdown affects the expression of other NF- $\kappa$ B subunits. Western blot analysis of the expression of individual NF- $\kappa$ B family members. Protein expression in cytoplasmic (CE) and nuclear portion (NE) was normalized against actin and Lamin A/C, respectively. 
A

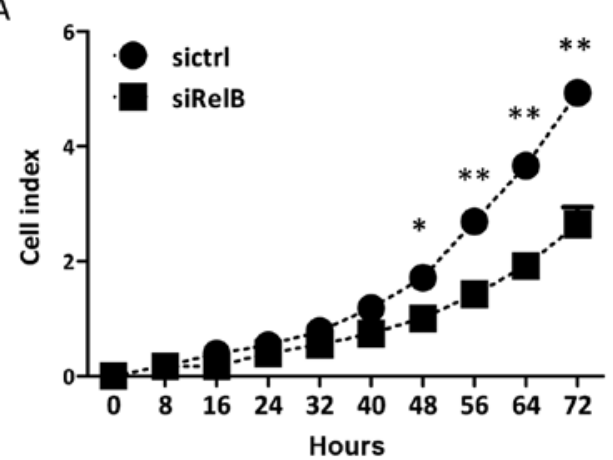

B

\begin{tabular}{c|ccc}
\hline & G0-G1 (\%) & S (\%) & G2-M (\%) \\
\hline sictrI & $66.15 \pm 2.60$ & $15.92 \pm 2.51$ & $16.48 \pm 0.73$ \\
siRelB & $60.63 \pm 0.96$ & $19.49 \pm 5.23$ & $18.47 \pm 3.72$ \\
\hline
\end{tabular}

C

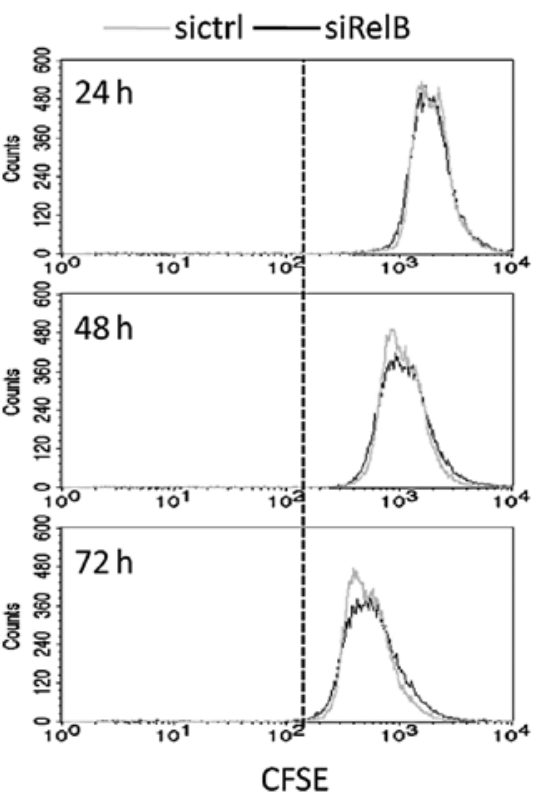

D

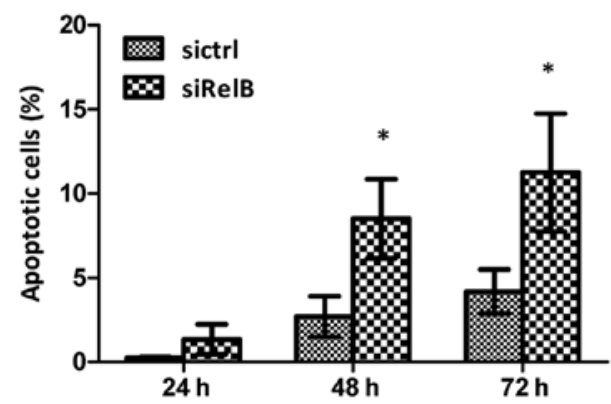

Figure 3. RelB knockdown inhibits growth and induces apoptosis of DU145 cells. (A) The cell growth curves of DU145-sictrl and DU145-siRelB cells, detected by xCelligence system. Each plate was inoculated with 10,000 cells and the cell growth was monitored continuously. Significant differences are indicated (Student's t-test, ${ }^{*} \mathrm{p}<0.05 ;{ }^{* *} \mathrm{p}<0.01$ ). (B) Flow cytometric analysis of the cell cycle between the two established cell lines. The table presents the data of three phases (G0-G1, S and G2-M). (C) The CFSE cell proliferation assay examined by flow cytometry at 24, 48 and $72 \mathrm{~h}$. (D) Flow cytometric analysis of apoptotic cells. Numbers represent mean values \pm SD from three individual experiments. Significant differences are indicated (Student's t-test, $\left.{ }^{*} \mathrm{p}<0.05\right)$.

binding complexes, an ELISA-based NF- $\kappa$ B activity assay was performed. The average RelB activity in nuclear extracts of DU145-siRelB was significantly decreased as compared with that in the DU145-sictrl cells, while the average RelA, p50, p52, and c-Rel activity was comparable (Fig. 1D).

Knockdown of RelB does not affect other $N F-\kappa B$ subunits. To investigate whether the RelB knockdown affected the expression of other NF- $\mathrm{BB}$ subunits, western blot analysis was carried out. As shown in Fig. 2, the expression levels of RelA and p50, contributing to the canonical NF- $\mathrm{B}$ activity, were comparable between the DU145-siRelB and DU145-sictrl cells at both cytoplasmic (CE) and nuclear fractions (NE). Similarly, the expression levels of p52 and c-Rel were not changed although the RelB expression was clearly reduced in the DU145-siRelB cells. The band densities for the western blot analysis were analyzed and compared between the DU145-siRelB and DU145-sictrl cells at both CE and NE, which further supported that the NF- $\kappa \mathrm{B}$ subunits was not affected by the RelB knockdown (data not shown). Thus, the data here indicated that the RelB knockdown by RNAi did not affect the expression of other NF- $\kappa \mathrm{B}$ family members.

Knockdown of RelB suppresses DU145 cell growth. Cell growth assay was performed by a real-time xCelligence system using E-plates to investigate whether RelB might 

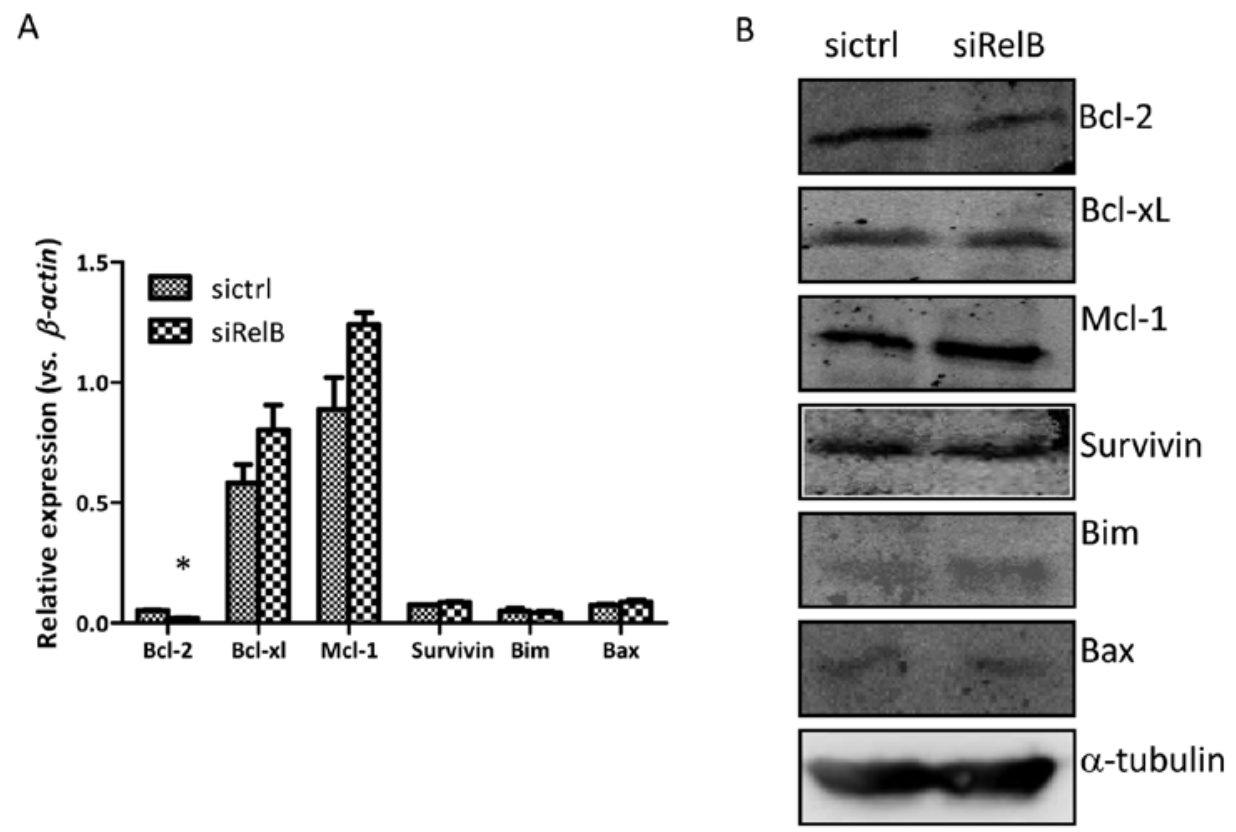

Figure 4. RelB knockdown regulates the expression of apoptosis-related protein. (A) qRT-PCR analysis of the mRNA expression of pro-apoptotic and antiapoptotic genes. Significant differences are indicated (Student's t-test, ${ }^{*}$ p $<0.05$ ). (B) Western blot analysis of pro-apoptotic and anti-apoptotic genes.

exert a biological activity on DU145 cell growth. As shown in Fig. 3A, the DU145-siRelB cells grew much slower than that of the DU145-sictrl cells, and there was a statistically significant difference between the two established cell lines after culturing for $48 \mathrm{~h}$ and later. The cell growth curve clearly indicated that RelB knockdown had suppressing effect on prostate cancer cell growth. The cell cycle assay and cellular DNA content measurement were performed by flow cytometry. The percentages of the DU145-siRelB cells in the three cell cycle phases (G0-G1, S and G2-M) were $60.63 \pm 0.96,19.49 \pm 5.23$ and $18.47 \pm 3.72 \%$; while those of the DU145-sictrl cells were $66.15 \pm 2.60,15.92 \pm 2.51$ and $16.48 \pm 0.73 \%$, respectively. There were no significant differences between the two groups in cell cycle progression (Fig. 3B).

To investigate whether the RelB might affect the proliferation capability of DU145 cells, a CFSE cell proliferation assay detected by flow cytometry was carried out. The fluorescence intensities of CFSE were attenuated in both established cell lines in a time-dependent manner. However, no significant differences were observed between the DU145-siRelB and the DU145-sictrl cells after culturing for 24, 48 and $72 \mathrm{~h}$ (Fig. 3C). Thus, RelB knockdown did not affect the cellular proliferation ability of DU145 prostate cancer cells.

The Annexin V/PI assay was carried out to quantitatively analyze the apoptosis. Both the two establish cell lines underwent spontaneous apoptosis in a time-dependent manner. As showed in Fig. 3D, the percentages of apoptotic cells in the DU145-sictrl group were $0.24 \pm 0.05,2.69 \pm 1.20$ and $4.17 \pm 1.30 \%$ at 24, 48 and $72 \mathrm{~h}$, respectively; while those in the DU145siRelB group were $1.33 \pm 0.89,8.50 \pm 2.35$ and $11.25 \pm 3.50 \%$. Spontaneous apoptosis was markedly increased in the DU145siRelB cells, and there were statistically significant differences between the two cell lines in the apoptosis rate at both 48- and 72-h time-points. Therefore, the data here showed that RelB knockdown slowed down the cell growth of DU145 cells. The enhanced apoptosis contributed to the inhibited cell growth upon downregulation of RelB expression in DU145 prostate cancer cells.

RelB regulates apoptosis-related protein. To gain insights into the mechanism that RelB knockdown enhanced prostate cancer cell apoptosis, the mRNA expressions of several pro-apoptotic genes including Bax and Bim, as well as anti-apoptotic genes including $\mathrm{Bcl}-2, \mathrm{Bcl}-\mathrm{xL}, \mathrm{Mcl}-\mathrm{l}$ and Survivin were examined by qRT-PCR analysis. As shown in Fig. 4A, the mRNA expression of the anti-apoptotic gene, $\mathrm{Bcl}-2$, was distinctly reduced in the DU145-siRelB cells compared to that of the DU145-sictrl cells, which was in line with the reduced Bcl-2 protein expression measured by western blot analysis (Fig. 4B). The mRNA and protein expression of other apoptosis-associated genes such as the pro-apoptotic genes Bim and Bax, and the anti-apoptotic genes Bcl-xL, Mcl-1 and Survivin appeared to be independent of RelB status in the DU145 prostate cancer cells (Fig. 4). Collectively, our data indicate that RelB exerted a crucial apoptosis resistance function in DU145 cells by regulating an

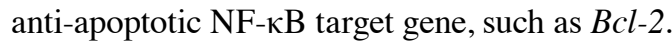

RelB affects the migration and invasion of DU145 cells. In order to investigate whether RelB expression level might affect the migration ability of DU145 prostate cancer cells, the cell migration assay was measured dynamically using the real-time xCelligence system. As shown in Fig. 5A, the DU145-siRelB cells migrated markedly slower than the DU145-sictrl cells during the 24-h continuous monitoring. There were significantly statistical differences in the migration assay between the two established cell lines. The in vitro scratch assay was also carried out to evaluate the migration ability of DU145 cells. A scratched cell monolayer was generated in both cell lines and images were captured after culturing for $72 \mathrm{~h}$. At the 72-h time-point of the assay, it 
A

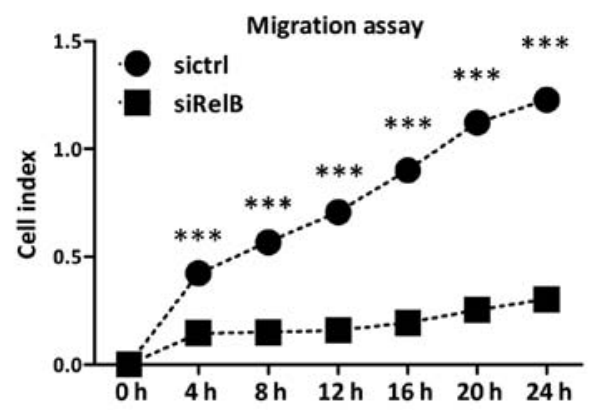

B

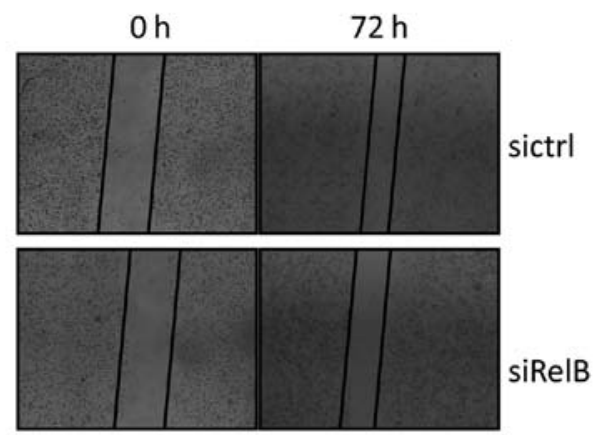

Figure 5. RelB knockdown hampers the migration of DU145 cells. (A) The migration ability of DU145-sictrl and DU145-siRelB cells, detected by a real-time xCelligence system using CIM-plates. Each plate was inoculated with 6,000 cells and the migration was monitored for $24 \mathrm{~h}$. Significant differences are indicated (Student's t-test, ${ }^{* * *} \mathrm{p}<0.001$ ). (B) Analysis of the migration ability of the two established cell lines detected by the wound healing assay at $72 \mathrm{~h}$.

A

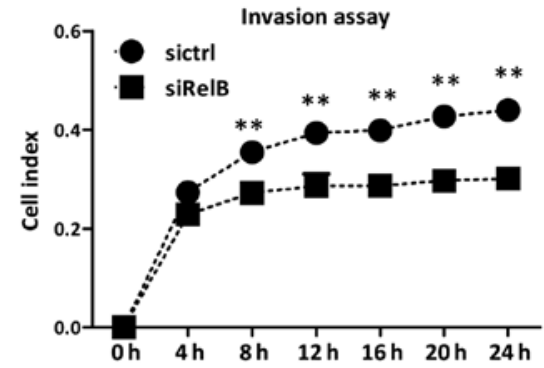

B

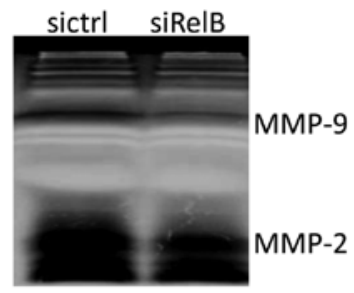

D

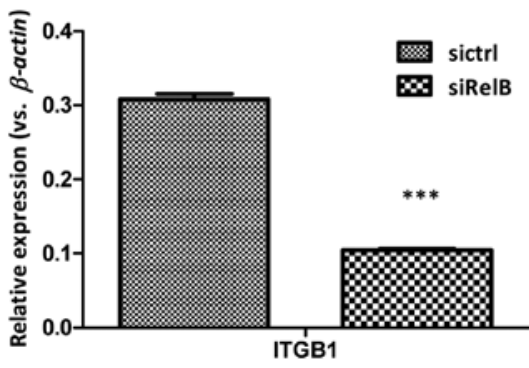

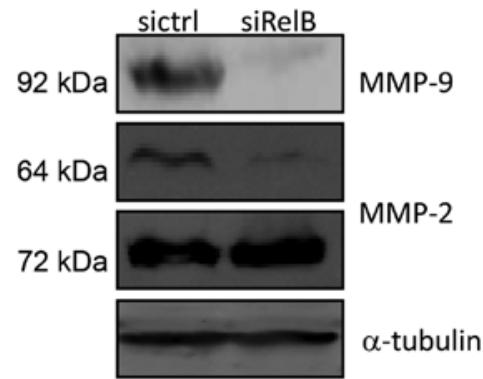

$E$

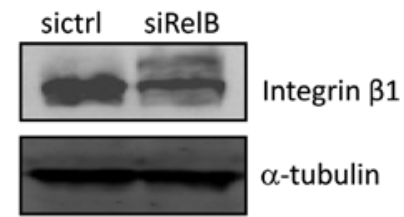

Figure 6. RelB knockdown attenuates the invasion ability of DU145 cells. (A) Analysis of the invasion ability of the two established cell lines, detected by a real-time xCelligence system using Matrigel (1:40 dilution)-coated CIM-plates. Each plate was inoculated with 6,000 cells and the invasion ability was monitored for $24 \mathrm{~h}$. (B) Gelatin zymography experiments analysis of the activity of MMP-2 and MMP-9. (C) Western blot analysis of MMP-2 and MMP-9. (D) qRT-PCR analysis of ITGB1 mRNA level. (E) Western blot analysis of the protein level of integrin $\beta$-1. $\alpha$-tubulin expression is shown as a loading control.

was shown that the DU145-siRelB cells migrated from the edge towards the scratch center much slower than that of the
DU145-sictrl cells (Fig. 5B), indicating a defected migratory ability of the DU145-siRelB cells. 
A
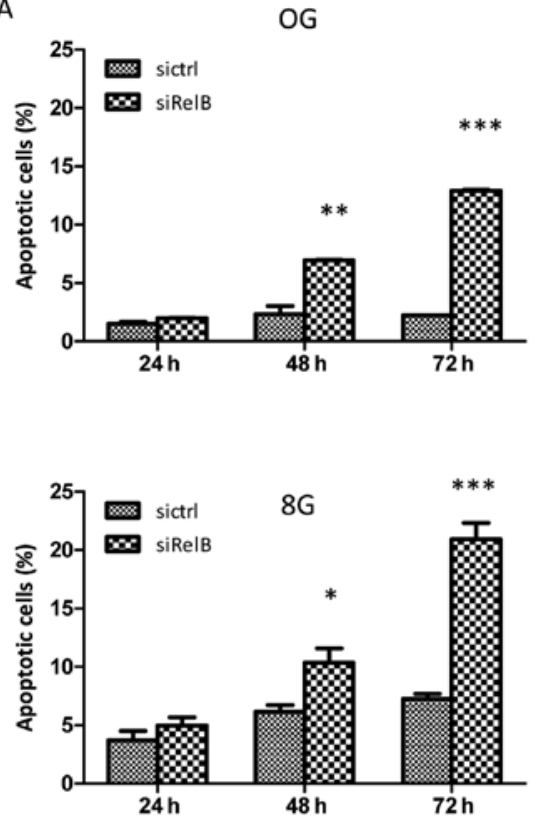

4G

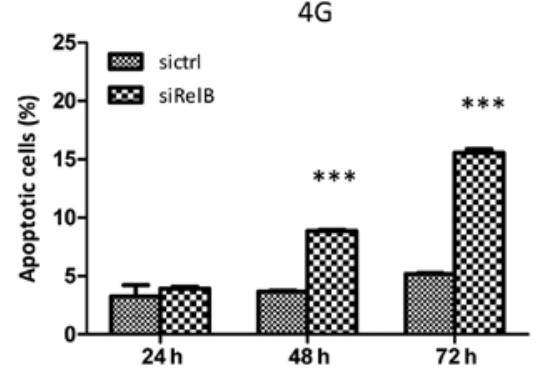

B

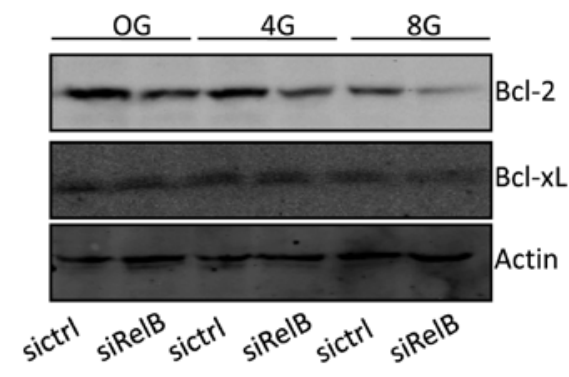

C

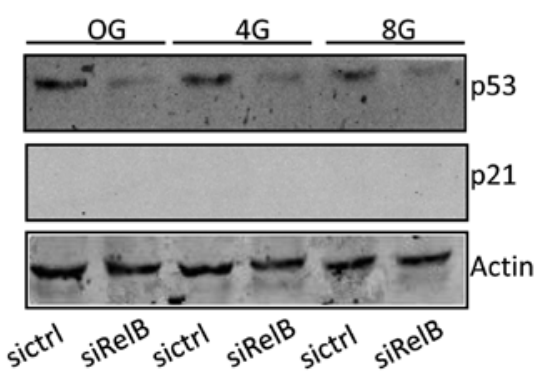

Figure 7. RelB knockdown increases the radio-sensitivity of DU145 cells. (A) Analysis of apoptotic cells at 24, 48 and $72 \mathrm{~h}$ after 0,4 and 8 Gy of irradiation exposure, examined by flow cytometry. Significant differences are indicated (Student's t-test, ${ }^{*} \mathrm{p}<0.05 ;{ }^{* *} \mathrm{p}<0.01$, and $\left.{ }^{* * *} \mathrm{p}<0.001\right)$. (B) Western blot analysis of the protein levels of Bcl-2 and Bcl-xL at $72 \mathrm{~h}$ after 0,4 and $8 \mathrm{~Gy}$ of irradiation exposure, normalized against actin. (C) Western blot analysis of the protein levels of p53 and p21 at $72 \mathrm{~h}$ after 0,4 and 8 Gy of irradiation exposure, normalized against actin.

The cell invasion assay was also performed by the real-time xCelligence system using Matrigel (dilution at 1:40)-coated CIM-plates. As shown in Fig. 6A, the DU145siRelB cells migrated and invaded through the Matrigel clearly slower than the DU145-sictrl cells during the 24-h continuous observation. There were statistically significant differences between the two established cell lines at the time-points of 8, 12, 16, 20 and $24 \mathrm{~h}$. Gelatin zymography experiment was further performed to examine the relative amounts of active and inactive gelatinase MMP-2 or MMP-9, members of the matrix metalloproteinases family. As shown in Fig. 6B, the activity of MMP-2 and MMP-9 was evidently reduced in the DU145-siRelB cells compared to that of the DU145-sictrl cells, supporting the diminished invasion ability of cells. Moreover, the expression of MMP-2 and MMP-9 in the DU145-siRelB at protein level was also evidently lower than the DU145-sictrl cells (Fig. 6C).

Integrin $\beta-1$, encoded by the ITGBI gene, belongs to the family of heterodimeric transmembrane cell surface receptors. Integrin $\beta-1$ activation is a key regulator in the switch from cellular dormancy to metastatic growth in vitro and in vivo. The ITGBI expression at mRNA level was significantly decreased in the DU145-siRelB cells than that of the DU145-sictrl cells, consistently; the protein level of integrin $\beta-1$ was also reduced in the DU145-siRelB cells (Fig. 6D and E). Thus, these results indicated that RelB knockdown hindered the migration and invasion abilities of DU145 prostate cancer cells, and the downregulated integrin $\beta-1$ was implicated in these processions.

RelB regulates the radio-sensitivity of DU145 cells. Several pieces of evidence have demonstrated that ionizing irradiation can cause cytotoxicity to prostate cancer cells through diverse mechanisms. In order to investigate the role of RelB in the radio-sensitivity of prostate cancer cells, DU145 cells were subjected to exposure at 4 and 8 Gy doses of ionizing irradiation followed by cell survival assay. As shown in Fig. 7A, the frequencies of apoptotic cells in the two established cell lines were increased in a time-dependent and a dose-dependent manner. Response to 4 or 8 Gy doses of ionizing irradiation, the DU145-siRelB cells had a much higher apoptosis rate than that of the DU145-sictrl cells. 


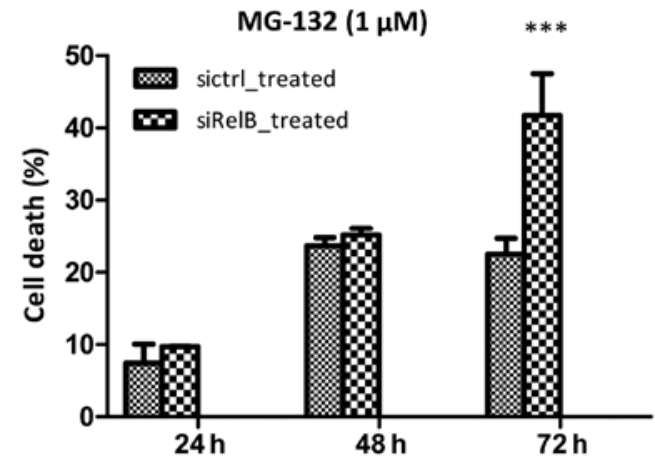

Figure 8. RelB knockdown augments proteasome inhibitor-induced cell death. (A) Cell death was measured upon flow cytometric analysis of PI-positive cells at 24, 48 and $72 \mathrm{~h}$ after treated with MG-132 $(1 \mu \mathrm{M})$ Percentages of relevant populations are indicated. Numbers represent mean values \pm SD from three individual experiments. Significant differences are indicated (Student's t-test, $\left.{ }^{* * *} \mathrm{p}<0.001\right)$.

There were statistically significant differences between the two cell lines in the apoptosis rate after expose to irradiation for 48 and $72 \mathrm{~h}$.

Consistent with the results shown in Fig. 4B, the expression of one of the anti-apoptotic proteins, Bcl-2, was clearly reduced in the DU145-siRelB cells. The expression level of $\mathrm{Bcl}-2$ was unchanged in response to $4 \mathrm{~Gy}$ doses of ionizing irradiation, and was slightly decreased in response to $8 \mathrm{~Gy}$ doses in the DU145-sictrl cells. However, the expression level of Bcl-2 was decreased in a dose-dependent manner in the DU145-siRelB cells in response to ionizing irradiation. Another anti-apoptotic protein, Bcl-xL, was expressed at a similar level between the DU145-sictrl and DU145-siRelB cells. Irradiation exposure did not affect the expression levels of Bcl-xL in the DU145-sictrl or the DU145-siRelB cells (Fig. 7B). Cell cycle distribution was not significantly affected in both DU145-sictrl and DU145-siRelB cells in response to irradiation. The endogenous expression of p53 was reduced in the DU145-siRelB cells compared to that in the DU145-sictrl cells. The expression level of p53 was not changed in DU145-sictrl or DU145-siRelB cells after exposure to ionizing irradiation. The expression of $\mathrm{p} 21$ could not be detected in DU145-sictrl or DU145-siRelB cells (Fig. 7C).

RelB augments proteasome inhibitor-induced cell death. In order to detect whether RelB might affect the proteasome inhibitor-induced cell death of prostate cancer cells, both cell lines were treated with MG-132 (1 $\mu \mathrm{M})$. MG-132, a proteasome inhibitor, caused considerable cell death in both cell lines in a time-dependent manner (Fig. 8). After treated with MG-132 for 24 and $48 \mathrm{~h}$, the cell death in the DU145siRelB cells was $9.71 \pm 0.10$ and $25.18 \pm 0.93 \%$, respectively, which were similar to that in DU145-sictrl cells, 7.45 \pm 2.61 and $23.69 \pm 1.12 \%$. Nevertheless, the percentage of cell death in the DU145-siRelB cells was $41.75 \pm 5.75 \%$ after treated with MG-132 for $72 \mathrm{~h}$, while that in DU145-sictrl cells was only $22.53 \pm 2.18 \%$. There was statistically significant difference between the two established cell lines in the cell death rate after treated with MG-132 for $72 \mathrm{~h}$. Therefore, shRNA targeting RelB in the DU145 prostate cancer cells sensitized proteasome inhibitor-treatment.

\section{Discussion}

In this study, how the non-canonical NF- $\kappa \mathrm{B}$ subunit RelB, regulates diverse biological behaviors of prostate cancer cells was extensively examined. RelB knockdown in the DU145 human androgen-independent prostate cancer cells using shRNA approach influenced multiple biological processes. The suppressed functions of the RelB knockdown in prostate cancer cell growth, migration, invasion, and the acquired chemo-sensitivity were evidently observed in vitro. We provide several lines of evidence that RelB plays an important role in prostate cancer progression.

RelA, a canonical NF- $\kappa$ B subunit, is considered as an independent biomarker of many human malignances including prostate cancer. While RelA has been thoroughly examined in the initiation and progression of prostate cancer, RelB, representing the non-canonical NF- $\kappa \mathrm{B}$ activity has been less studied in prostate cancer. Similar to the highly aggressive prostate cancer PC-3 cell line, the aggressive DU145 cell line is also androgen-independent and express both the canonical and the non-canonical NF- $\mathrm{BB}$ signaling molecules.

To determine the relevance of endogenous RelB activation in diverse aspects in prostate cancer cells, RelB was knocked down in DU145 cells using shRNA approach in the study. The stable downregulation of RelB expression in DU145 cells did not affect the expression of other NF- $\kappa \mathrm{B}$ family members including RelA, c-Rel, NF- $\kappa \mathrm{B} 1$, and NF- $\mathrm{N} 2$. We observed significant inhibition of cell growth upon introducing shRNARelB into DU145 cells and found that the enhanced apoptosis contributed to the slow cell growth. Nevertheless, the cell cycle distribution and cellular proliferation were not affected by the knockdown of RelB in DU145 cells. Previously, our lab has reported that not only RelA but also RelB, subunits of $\mathrm{NF}-\kappa \mathrm{B}$ family, played an important role in the cellular behaviors of chronic lymphocytic leukemia (CLL) cells from bone marrow. The strength of RelB activity positively regulated the cell survival in CLL cells. High RelB activity, together with RelA activity, maintains the basal survival of CLL cells. In addition, the induction of RelA and RelB expression in the nucleus is responsible for better survival of CLL cells supported by bone marrow stromal cells (16). Similar observations were recently reported that RelB-silencing decreases the viability of Hodgkin lymphoma (HL) cells significantly while the RelA activity is intact in HL cells (17). Silencing of RelB transiently in DU145 cells through RNA interference method, our lab has previously observed that RelB plays a modest role in regulating the spontaneous cell death while RelA mediates a selective survival advantage in DU145 prostate cancer cells (8). It has been reported that inhibiting RelB in PC-3 cells by small interfering RNA targeting reduces cell growth and IL-8 expression, indicating a cancer-supportive role of RelB in prostate cancer cells $(18,19)$. Therefore, our findings here were consistent with previous reports that high RelB expression supports the survival of malignant cells when the endogenous RelA activity is constitutively activated. However, the detailed underlying mechanism is still undefined.

To further understand the mechanism of enhanced apoptosis upon introducing of shRNA-RelB into DU145 cells, we examined a series of apoptosis-related molecules and finally 
focused on the NF- $\mathrm{KB}$ regulated anti-apoptotic gene, Bcl-2. Both the western blot and qRT-PCR analysis pointed to a clear downregulation of the Bcl-2 when RelB expression was blocked. This was expected to trigger the apoptosis pathway, contributing to enhanced apoptosis in the DU145-siRelB prostate cancer cells.

The regulation of cell survival by RelB has also been found in multiple myeloma (MM) cells. RelB-dependent induction in cIAP2, an anti-apoptotic NF- $\mathrm{KB}$ target gene, constitutes a strong pro-survival signal in MM cell lines and primary cells from MM patients through its anti-apoptotic role. To a lesser extent, the expression of other anti-apoptotic genes such as $B c l-x L$ and $B c l-2$ are also increased in MM cells (20). Abundant RelB protein is expressed in highly aggressive human breast cancer cell lines, for example MDA-MB-231 and Hs578T cells. RelB promotes cell survival to irradiation and doxorubicin, likely due to the induction of anti-apoptotic genes such as Survivin, $\mathrm{MnSOD}$, and Bcl-2 in breast cancer cells (12). Here, we presented evidence that RelB knockdown in DU145 prostate cancer cells inhibited cell growth, and the dysregulated expression of apoptotic-related protein such as Bcl-2 played important roles.

Furthermore, we showed that RelB knockdown suppressed the migration and invasion abilities of DU145 prostate cancer cells. Very few studies have reported the involvement of RelB in the migration and invasion of malignant cells. Apigenin could suppress migration of PC-3 prostate cancer cells by inhibiting the IKK $\alpha / \mathrm{NF}-\kappa \mathrm{B}$ activation (13). The nuclear IKK $\alpha$ enhances metastasis by repressing transcription of the Maspin gene (14), which inhibits cancer metastasis by suppressing invasion and motility (21). RelB is found to repress the expression of Maspin in prostate cancer cells, however, the detailed investigation in this process still demands more efforts (8). In breast cancer cell lines, RelB represses the expression of estrogen receptor $\alpha(\mathrm{ER} \alpha)$ via the induction of the B-lymphocyte-induced maturation protein (Blimp1), which promotes a more migratory phenotype in breast and lung cancer cells $(22,23)$. Notably, RelB promotes a more invasive phenotype in ER $\alpha$-negative cancer via the induction of the anti-apoptotic gene, Bcl-2. RelB also functions in epithelial to mesenchymal transition (EMT) in breast cancer cells, and Bcl-2 is an important downstream mediator (24). Protection from apoptosis by $\mathrm{Bcl}-2$ has been proposed to have an important role in promoting metastasis. Knockdown of adhesion G protein-coupled receptors (ADGRG2) in Hs578T and MDA-MB-231 breast cancer cells causes a strong reduction in cell adhesion and subsequent cell migration, which is associated with RelB reduction (25). A recent report suggests that RelB plays a critical role in promoting fibroblast migration prolonged tumor necrosis factor (TNF)- $\alpha$ treatment. The migration-associated gene, the matrix metallopeptidase 3 (MMP-3) was identified as a novel target of RelB (26). For the first time, we provided evidence that the RelB played a positive role in regulating the migration and invasion of DU145 prostate cancer cells, and therefore it functioned indeed as an oncogene in prostate cancer cells.

Diverse molecular regulators, including adhesion receptor families, receptor tyrosine kinase, cytoskeleton protein, adaptors, and signaling molecules, are involved in the regulation of migration and invasion of cancer cells. Interestingly, we found that the expression of integrin $\beta-1$ was downregulated in the DU145-siRelB cells. Integrin $\beta$-1, encoded by the ITGBI gene, belongs to the family of heterodimeric transmembrane cell surface receptors that contain $18 \alpha$ and $8 \beta$ subunits and bridge the interaction between cell-cell and cell-extracellular matrix (ECM). Overexpression of integrin $\beta-1$ has been found in many epithelial malignancies during invasion, angiogenesis, and metastasis. Integrin $\beta-1$ silencing suppresses lung cancer cell invasion and metastasis in vitro and in vivo (27). Integrin $\beta-1$ and integrin-induced autophosphorylation of focal adhesion kinase (FAK) are increased in prostate cancer cells, correlating with metastatic potential in vivo (28). There is a direct interaction between Maspin and integrin $\beta-1$ by the reactive centre loop of Maspin (29). The activation of the small cell lung cancer (SCLC) H69 cell line by lipopolysaccharide (LPS) causes the induction of RelB and p100 expression. Blocking RelB expression prevents the induction of integrin $\beta-1$ and the attachment of $\mathrm{H} 69$ cells. Since the ITGB1 promoter does not contain NF-kB consensus sequences, it is conceivable that the LPS-mediated induction of integrin $\beta-1$ could be through the expression of HIF-1 $\alpha$ (30). To understand whether similar mechanism would occur in the prostate cancer cells is warranted.

Radiotherapy is one of the most commonly used therapies for prostate cancer. However, radio-recurrent prostate cancer and a poor long-term prognosis are experienced by many prostate cancer patients, as $\sim 30-40 \%$ of those individuals treated with potentially curative doses develop radio-resistance (31). RelB complex, representing the alternative NF- $\kappa \mathrm{B}$ activity, has been shown to confer radio-resistance in prostate cancer, in part, by stimulating the expression of MnSOD. Selective blocking RelB activation by SN52 suppresses MnSOD expression and sensitizes PC-3 prostate cancer cells to radiation $(10,32)$. Bcl-xL, an NF- $\mathrm{BB}$ target anti-apoptotic gene, whose response is widely thought to be involved in both chemo-resistance and radio-resistance, has also been modulated by RelB in malignant cells. As shown in a recent study, RelB-siRNA transfection into murine RM-1 prostate cancer cells increases radiation-induced apoptosis by inhibiting the expression of the $B c l-x L$ gene (33). In our study, RelB knockdown in DU145 prostate cancer cells sensitized radiation-induced apoptosis, which was in line with previous studies. Unfortunately, we could not perform the clonogenic survival assay successfully for DU145-sictrl or DU145-siRelB cells after irradiation. Though, both DU145-sictrl and DU145-siRelB cells without irradiation formed colonies successfully. The number of colonies was evidently low when cultured using the DU145siRelB cells, indicating the poor survival capacity (data not shown). A marked reduction of Bcl-2 expression was observed in response to irradiation in the presence of RelB knockdown, nevertheless, changes in the expression of Bcl-xL in response to irradiation were not detect in the DU145-sictrl or DU145-siRelB cells. The expression of Bcl-2 was also slightly reduced in the DU145-sictrl cells after exposure to 8-Gy doses of ionizing irradiation, which was correlated with the increased apoptosis. However, the expression level of Bcl-2 was decreased in a dose-dependent manner in the DU145siRelB cells in response to ionizing irradiation. The reduction of Bcl-2 level also corresponded to the induction of apoptosis. $\mathrm{Bcl}-2$ has been previously reported as a direct target of RelB in breast cancer cells (24). Bcl-2 plays an important role in radio- 
resistance of diverse cancer cells. The Bcl-2 protein expression after radiotherapy correlates with both response and survival. The Bcl-2 positive cancers show significantly poorer response than the Bcl-2 negative cancers after radiation (34). In this study, we found that the expression of $\mathrm{Bcl}-2$ was regulated by RelB, indicating that Bcl-2 is a potential target gene of RelB in prostatic cancer cells. The Bcl-2 expression was reduced both in the DU145-sictrl and DU145-siRelB cells after irradiation, although with different levels. The reduced $\mathrm{Bcl}-2$ expression correlated with the increased apoptosis and the improved radio-sensitivity after irradiation. Overall, when RelB was silenced in the DU145 cells, the radio-sensitivity was largely increased due to the reduction of $\mathrm{Bcl}-2$. However, the potential mechanism underlying the reduction of Bcl-2 after irradiation in the DU145 cells demands further study. The cell cycle distribution was not significantly affected in DU145-sictrl or DU145-siRelB cells. The expression of p53 was reduced in the DU145-siRelB cells compared to that in the DU145-sictrl cells. The expression level of p53 was not changed in DU145-sictrl or DU145-siRelB cells after exposure to ionizing irradiation. The expression of p21 could not be detected in DU145-sictrl or DU145-siRelB cells.

Besides its role in carcinogenesis of human cancers, RelB might play a role in chemo-sensitivity. STI571, a tyrosine kinase inhibitor, is effective for treating androgen-independent, but not androgen-responsive prostate cancer cells in the context of high levels of the RelB activity (35). Targeting of the NF- $\kappa \mathrm{B}$ signaling pathway is proposed as a promising therapeutic choice in cancer. An indirect approach to target $\mathrm{NF}-\kappa \mathrm{B}$ is using proteasome inhibitors such as PS-341 (bortezomib) or MG-132, which induce apoptosis in a variety of malignant cells. Bortezomib manifests remarkable anticancer activity in several hematological malignancies such as MM. Bortezomib is less effective in prostate cancer and other solid tumors; however, the mechanisms have not been fully understood. Recent studies suggest that bortezomib treatment in PC-3 and DU145 prostate cancer cells unexpectedly induces the expression of pro-inflammatory chemokine IL-8, which promotes cancer cell proliferation, survival, and angiogenesis. Moreover, bortezomib increases nuclear accumulation of IKK $\alpha$, and suppression of IKK $\alpha$ protein levels and enzymatic activity significantly decreases the bortezomib induced IL-8 expression. Thus, the inactivation of the non-canonical $\mathrm{NF}-\kappa \mathrm{B}$ activity is expected to convey better effects of proteasome inhibitor $(36,37)$. In this study, we illustrated that RelB knockdown in DU145 cells enhanced chemo-sensitivity to the proteasome inhibitor MG-132. Treated with MG-132 for $72 \mathrm{~h}$, the DU145-siRelB cells showed much more cell death than the DU145-sictrl cells, suggesting a supporting role of RelB in proteasome inhibitor resistance in prostate cancer cells. It has been reported that inhibition of RelB may be one of the principal mechanisms of action of proteasome inhibitor in MM cells (38). Therefore, low RelB expression in DU145 prostate cancer cells was positively correlated with proteasome inhibitor sensitivity. One of the main functions of proteasome inhibitor is the suppressed proteasomal degradation of $\mathrm{I} \kappa \mathrm{B} \alpha$, resulting in the inhibition of $\mathrm{NF}-\kappa \mathrm{B}$ activity and expression of $\mathrm{NF}-\kappa \mathrm{B}$ target genes. NF- $\kappa \mathrm{B}$ activity is constitutively increased in metastatic prostate cancer cells through the increased activation of IKK, resulting in the increased cell survival and resistance to chemotherapy. Proteasome inhibitor has so far failed to exhibit a significant clinical activity in prostate cancer patients; the mechanisms are largely unknown. It has been reported that proteasome inhibitor could increase the nuclear levels of RelA in prostate cancer cells due to preventing the proteasomal degradation of nuclear RelA. Targeting both IKK $\alpha$ may increase the proteasome inhibitor effectiveness in androgen-independent prostate cancer treatment. IKK $\alpha$ is a critical molecule in the activation of the non-canonical $\mathrm{NF}-\kappa \mathrm{B}$ signaling pathway, leading to the activation of RelB predominantly. Therefore, it is assumed that targeting RelB might improve proteasome inhibitor sensitivity. Nevertheless, the molecular mechanism underling the improved sensitivity to proteasome inhibitor treatment when RelB is silenced in the prostatic cancer cells is warranted.

The above findings establish a key tumor-promoting role of the non-canonical NF- $\kappa \mathrm{B}$ activity subunit RelB in the carcinogenesis of prostate cancer. Our data shed light on unexplored aspects of RelB in prostate cancer cells. RelB controlled the spontaneous and radiation-induced cell survival of prostate cancer cells by regulating Bcl-2 predominantly. RelB played a supportive role in the migration and invasion abilities of prostate cancer cells by regulating integrin $\beta-1$. Given the potent effects on cell growth, migration, invasion, and chemo-resistance, RelB represents an attractive target for cancer therapy. To address the function of RelB in vivo, further studies will be performed in the future.

\section{Acknowledgements}

This study was supported by the National Natural Science Foundation of China (F.G., grant no. 81172433) and the Natural Science Foundation of Jiangsu Provincial (F.G., grant no. BK20151211).

\section{References}

1. Siegel RL, Fedewa SA, Miller KD, Goding-Sauer A, Pinheiro PS, Martinez-Tyson D and Jemal A: Cancer statistics for Hispanics/ Latinos, 2015. CA Cancer J Clin 65: 457-480, 2015.

2. Napetschnig $\mathbf{J}$ and Wu H: Molecular basis of NF-kB signaling. Annu Rev Biophys 42: 443-468, 2013.

3. Weih $\mathrm{F}$ and Caamaño J: Regulation of secondary lymphoid organ development by the nuclear factor-kappaB signal transduction pathway. Immunol Rev 195: 91-105, 2003

4. Perkins ND: The diverse and complex roles of NF- $\kappa B$ subunits in cancer. Nat Rev Cancer 12: 121-132, 2012.

5. Karin M: Nuclear factor-kappaB in cancer development and progression. Nature 441: 431-436, 2006.

6. Suh J and Rabson AB: NF-kappaB activation in human prostate cancer: Important mediator or epiphenomenon? J Cell Biochem 91: 100-117, 2004.

7. Lessard L, Bégin LR, Gleave ME, Mes-Masson AM and Saad F: Nuclear localisation of nuclear factor-kappaB transcription factors in prostate cancer: An immunohistochemical study. Br J Cancer 93: 1019-1023, 2005.

8. Guo F, Kang S, Zhou P, Guo L, Ma L and Hou J: Maspin expression is regulated by the non-canonical NF- $\kappa \mathrm{B}$ subunit in androgeninsensitive prostate cancer cell lines. Mol Immunol 49: 8-17, 2011.

9. Lessard L, Saad F, Le Page C, Diallo JS, Péant B, Delvoye N and Mes-Masson AM: NF-kappaB2 processing and p52 nuclear accumulation after androgenic stimulation of $\mathrm{LNCaP}$ prostate cancer cells. Cell Signal 19: 1093-1100, 2007.

10. Holley AK, Xu Y, St Clair DK and St Clair WH: RelB regulates manganese superoxide dismutase gene and resistance to ionizing radiation of prostate cancer cells. Ann NY Acad Sci 1201: 129-136, 2010. 
11. Xu Y, Fang F, St Clair DK, Josson S, Sompol P, Spasojevic and St Clair WH: Suppression of RelB-mediated manganese superoxide dismutase expression reveals a primary mechanism for radiosensitization effect of 1alpha,25-dihydroxyvitamin $\mathrm{D}(3)$ in prostate cancer cells. Mol Cancer Ther 6: 2048-2056, 2007.

12. Mineva ND, Wang X, Yang S, Ying H, Xiao ZX, Holick MF and Sonenshein GE: Inhibition of RelB by 1,25-dihydroxyvitamin D3 promotes sensitivity of breast cancer cells to radiation. J Cell Physiol 220: 593-599, 2009.

13. Shukla S, Kanwal R, Shankar E, Datt M, Chance MR, Fu P, MacLennan GT and Gupta S: Apigenin blocks IKK $\alpha$ activation and suppresses prostate cancer progression. Oncotarget 6: 31216-31232, 2015.

14. Luo JL, Tan W, Ricono JM, Korchynskyi O, Zhang M, Gonias SL, Cheresh DA and Karin M: Nuclear cytokine-activated IKKalpha controls prostate cancer metastasis by repressing Maspin. Nature 446: 690-694, 2007.

15. Guo F, Sun A, Wang W, He J, Hou J, Zhou P and Chen Z: TRAF1 is involved in the classical NF-kappaB activation and CD30induced alternative activity in Hodgkin's lymphoma cells. Mol Immunol 46: 2441-2448, 2009.

16. Xu J, Zhou P, Wang W, Sun A and Guo F: RelB, together with RelA, sustains cell survival and confers proteasome inhibitor sensitivity of chronic lymphocytic leukemia cells from bone marrow. J Mol Med Berl 92: 77-92, 2014.

17. Ranuncolo SM, Pittaluga S, Evbuomwan MO, Jaffe ES and Lewis BA: Hodgkin lymphoma requires stabilized NIK and constitutive RelB expression for survival. Blood 120: 3756-3763, 2012.

18. Xu Y, Josson S, Fang F, Oberley TD, St Clair DK, Wan XS, Sun Y, Bakthavatchalu V, Muthuswamy A and St Clair WH: RelB enhances prostate cancer growth: Implications for the role of the nuclear factor-kappaB alternative pathway in tumorigenicity. Cancer Res 69: 3267-3271, 2009.

19. Xu Y, Fang F, St Clair DK and St Clair WH: Inverse relationship between PSA and IL- 8 in prostate cancer: An insight into a NF-kB-mediated mechanism. PLoS One 7: e32905, 2012.

20. Cormier F, Monjanel H, Fabre C, Billot K, Sapharikas E, Chereau F, Bordereaux D, Molina TJ, Avet-Loiseau H and Baud V: Frequent engagement of RelB activation is critical for cell survival in multiple myeloma. PLoS One 8: e59127, 2013.

21. Zhou J, Hualong Q, Zhou P and Guo F: Different maspin functions in the lung adenocarcinoma A549 and SPC-A1 cell lines. Int J Mol Med 36: 1440-1448, 2015

22. Wang X, Belguise K, O'Neill CF, Sánchez-Morgan N, Romagnoli M, Eddy SF, Mineva ND, Yu Z, Min C, TrinkausRandall V, et al: RelB NF-kappaB represses estrogen receptor alpha expression via induction of the zinc finger protein Blimp1. Mol Cell Biol 29: 3832-3844, 2009.

23. Yu Z, Sato S, Trackman PC, Kirsch KH and Sonenshein GE: Blimp1 activation by AP-1 in human lung cancer cells promotes a migratory phenotype and is inhibited by the lysyl oxidase propeptide. PLoS One 7: e33287, 2012.

24. Wang X, Belguise K, Kersual N, Kirsch KH, Mineva ND, Galtier F, Chalbos D and Sonenshein GE: Oestrogen signalling inhibits invasive phenotype by repressing RelB and its target BCL2. Nat Cell Biol 9: 470-478, 2007.
25. Peeters MC, Fokkelman M, Boogaard B, Egerod KL, van de Water B, IJzerman AP and Schwartz TW: The adhesion G protein-coupled receptor G2 (ADGRG2/GPR64) constitutively activates SRE and NFKB and is involved in cell adhesion and migration. Cell Signal 27: 2579-2588, 2015.

26. Authier H, Billot K, Derudder E, Bordereaux D, Rivière P, Rodrigues-Ferreira S, Nahmias C and Baud V: IKK phosphorylates RelB to modulate its promoter specificity and promote fibroblast migration downstream of TNF receptors. Proc Nat Acad Sci USA 111: 14794-14799, 2014.

27. Wang XM, Li J, Yan MX, Liu L, Jia DS, Geng Q, Lin HC, $\mathrm{He} \mathrm{XH}, \mathrm{Li} \mathrm{JJ}$ and Yao M: Integrative analyses identify osteopontin, LAMB3 and ITGB1 as critical pro-metastatic genes for lung cancer. PLoS One 8: e55714, 2013.

28. Lee YC, Jin JK, Cheng CJ, Huang CF, Song JH, Huang M, Brown WS, Zhang S, Yu-Lee LY, Yeh ET, et al: Targeting constitutively activated $\beta 1$ integrins inhibits prostate cancer metastasis. Mol Cancer Res 11: 405-417, 2013.

29. Ravenhill L, Wagstaff L, Edwards DR, Ellis V and Bass R: G-helix of maspin mediates effects on cell migration and adhesion. J Biol Chem 285: 36285-36292, 2010.

30. Saito T, Sasaki CY, Rezanka LJ, Ghosh P and Longo DL: p52-independent nuclear translocation of RelB promotes LPS-induced attachment. Biochem Biophys Res Commun 391: 235-241, 2010.

31. Xie BX, Zhang H, Yu L, Wang J, Pang B, Wu RQ, Qian XL, Li SH, Shi QG, Wang LL, et al: The radiation response of androgen-refractory prostate cancer cell line C4-2 derived from androgen-sensitive cell line LNCaP. Asian J Androl 12: 405-414, 2010.

32. Xu Y, Fang F, St Clair DK, Sompol P, Josson S and St Clair WH: SN52, a novel nuclear factor-kappaB inhibitor, blocks nuclear import of RelB:p52 dimer and sensitizes prostate cancer cells to ionizing radiation. Mol Cancer Ther 7: 2367-2376, 2008.

33. Zhu L, Zhu B, Yang L, Zhao X, Jiang H and Ma F: RelB regulates Bcl-xL expression and the irradiation-induced apoptosis of murine prostate cancer cells. Biomed Rep 2: 354-358, 2014.

34. Harima Y, Harima K, Shikata N, Oka A, Ohnishi T and Tanaka Y: $\mathrm{Bax}$ and $\mathrm{Bcl}-2$ expressions predict response to radiotherapy in human cervical cancer. J Cancer Res Clin Oncol 124: 503-510, 1998.

35. Xu Y, Fang F, Sun Y, St Clair DK and St Clair WH: RelBdependent differential radiosensitization effect of STI571 on prostate cancer cells. Mol Cancer Ther 9: 803-812, 2010.

36. Manna S, Singha B, Phyo SA, Gatla HR, Chang TP, Sanacora S, Ramaswami S and Vancurova I: Proteasome inhibition by bortezomib increases IL-8 expression in androgen-independent prostate cancer cells: The role of IKK $\alpha$. J Immunol 191: 2837-2846, 2013

37. Singha B, Gatla HR, Manna S, Chang TP, Sanacora S, Poltoratsky V, Vancura A and Vancurova I: Proteasome inhibition increases recruitment of IкB kinase $\beta$ (IKK $\beta$ ), S536P-p65, and transcription factor EGR1 to interleukin-8 (IL-8) promoter, resulting in increased IL-8 production in ovarian cancer cells. J Biol Chem 289: 2687-2700, 2014

38. Garber K: Gene mutation revelation points to new target for myeloma treatment, studies say. J Natl Cancer Inst 99: 1362-1364, 2007. 